\title{
Design topology of a remote-controlled bi-directional rotation of an A.C. fan with speed control
}

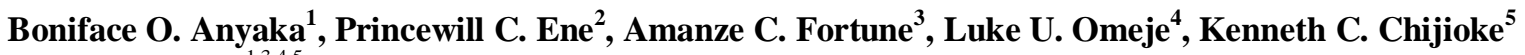 \\ ${ }_{1,3,4,5}$ Department of Electrical Engineering, University of Nigeria, Nsukka, Nigeria \\ ${ }^{2}$ Department of Electrical and Electronic Engineering, Enugu State University of Science and Technology, Nigeria
}

\begin{tabular}{l}
\hline Article Info \\
\hline Article history: \\
Received Jun 9, 2019 \\
Revised Oct 22, 2019 \\
Accepted Nov 1, 2019 \\
\hline
\end{tabular}

Keywords:

Bi-directional

Infrared sensor

Microcontroller

Remote control

Speed control

\begin{abstract}
The use of remote control for alternating current fans in homes/offices is one of the applications of electronics that enhances human comfort. It should therefore not be seen as luxury, rather, it should be taken as a basic requirement of life. In this study, the bi-directional rotation and speed control of ac fan was achieved using ardiuno microcontroller and tuned capacitors circuits. The use of the new state-of- the art technique in this work is significant because it helped in over-coming the drawbacks associated with the use of inductive, resistive and phase angle controlled regulators. The significance of this study will be of great benefit to physically challenged and aged persons who need to have their comforts in their various places of sitting. The designed topology of the work was executed and achieved. Reliability test carried out on the finished work showed better efficiency.
\end{abstract}

Copyright $\odot 2020$ Institute of Advanced Engineering and Science. All rights reserved.

\section{Corresponding Author:}

Boniface O. Anyaka

Department of Electrical Engineering

University of Nigeria, Nsukka, Enugu State, Nigeria.

Email: boniface.anyaka@unn.edu.ng

\section{INTRODUCTION}

The emergence of new technologies in the world of power electronics in recent times cannot be over-emphasized. Management of electrical equipment in our homes and offices has become easier and interesting due to the new state-of-the-art in recent research. According to [1], home automation allows every owner to decide how convenient it is to control his or her own appliances/equipment from any distance of choice. A home automation system is a combination of hardware and software technologies that enable control and management of appliances/equipment within an environment [2]. The term "Home Automation" is also known as "domotics" [3]. More details about home automation system can be seen in [4-15].

One of the electrical appliance used in homes/offices is the AC fan. It is one of the unavoidable electric appliance in our everyday life. One can harness the knowledge of home automation using power electronic principles to make life more suitable for a user of this home appliance [1]. The simultaneous control of speed and bi-directional rotation of an $\mathrm{AC}$ fan using Ardiuno microcontrolled remote system is what this study seek to solve.

This study is significant because it will add comfort to man's everyday living thus, removing the inconvenience of having to move around to operate a stationary fan regulator. More significantly, it will help the old and physically handicapped persons to operate their fans without getting up from their place of comfort. As a follow-up to previous studies, a critical analysis of the state-of-art in the theory and design of remote control fan regulators are discussed in this work. Other recent advances in relevant areas are also considered along-side with well accepted traditional theories and principles associated with the proposed design. A simple design and implementation of remote control fan regulator is presented in [1], however the speed of the fan was in one direction only. 
In the work of [16], a fan speed regulator which uses microcontroller to control a dc fan was presented. One drawback of the design was that the speed of the fan cannot be decided unless by the use of thermistor judgment in the power supply circuit powering the microcontroller. Also, with the modification of the circuit to power an AC fan, it was not possible to change the direction of rotation of the fan. In another study conducted by [17], a microcontroller was used to regulate the speed of an AC fan using input from two push buttons. One of the push buttons was used for increasing the speed of the fan, while the other one was used for reducing the speed of the fan.

The pitfall of this work was that the user has to walk all the way to where the push button controls are before he can operate the fan. This makes it difficult if not impossible for disabled people to use. Abel [18], in his work used PIC microcontroller to control the Speed of an AC fan by changing the firing angle of a triac as the room surrounding temperature changed. The temperature change in the surrounding was observed by a temperature sensor and interpreted by the microcontroller. The microcontroller made logical decisions about how fast the fan would rotate based on the temperature of the surrounding at a particular moment. In this work, a standing fan which cannot achieve change in direction of rotation unless its motor winding assembly is reoriented was used, hence only speed control was achieved. In system automation, speed control can be classified into four groups: inductive regulator, resistive regulator, phase angle-controlled regulator and capacitive regulator.

- Inductive regulator

Inductive voltage regulator is a type of electrical device in which the output voltage may vary from zero to a certain maximum value depending upon the ratio of the turns in the primary and secondary winding. The primary winding is connected to the circuit which is to be regulated and secondary is connected in series with the fan. This type of fan regulator has a tapping on the winding of a transformer and the inductive reactance is varied to achieve variation in speed. From the work of [19], the effective inductive reactance is the combination of the transformer and the fan inductances which gives a voltage drop across the fan and therefore, the speed is altered. At the highest speed, the fan is directly connected to the full AC mains supply and at the lowest speed, there is a high value inductor in series with the load. This method used here has an advantage of low heat power dissipation but has its disadvantages in giving low power factor, high cost of implementing and bulkiness due to its excessive components like the transformer. This work also lacks the function of being bi-directional in the rotation of the fan blades.

- $\quad$ Resistive regulator

Resistive regulator also known as conventional fan regulator consists of a wire wound resistor with different taps which is connected in series with the motor of the fan. The resistance depends upon the material of the conductor. The principle of operation is that of a rheostat or a resistance potential divider arrangement. As the steps (of the knob on the regulator box) decreases, the resistance of the circuit increases and lower power is applied to the fan [20,21]. Obviously, the power consumption by the fan will be less at lower speeds by this arrangement, but this is not an energy saving method. The voltage drop across the resistance is converted into heat losses (I2R), so the energy is dissipated in the form of heat. This wastage of energy which is a disadvantage of its usage is more at high resistance and lower speed condition.

Phase angle-controlled (TRIAC and DIAC) regulator

Due to the advancement in power electronic technology, the alternative design of fan regulator can be easily implemented to reduce the energy losses that are caused by conventional voltage regulators. In the work of [22], Phase angle-controlled regulators were used and it employed active devices such as DIAC (Diode Alternating Current) and TRIAC (Triode Alternating Current). The basic principle is to change the firing angle of the TRIAC in order to change the voltage across the fan. This type of regulator provides the step less control of the fan speed by deriving the required amount of power from the main supply at a given instant. Hence, the power is conserved rather than wasted unnecessarily.

The importance of the TRIAC and DIAC is its continuous and step less control of the fan speed, power saving is achieved at all the speeds by minimizing the energy losses. It consists of simple circuit which requires a smaller number of components and it is efficient as compared with resistive type due to lower power consumption. Its disadvantages are that its speed control is not linear and it is expensive. It produces humming sound that is disturbing and has higher failure rate as active devices are susceptible to power supply. Also, it has transients and interference which causes EMI/RFI (electromagnetic/radio frequency interferences) creating disturbances in television and radio sets.

- The capacitor regulators

From the three-different method of control reviewed, we could overcome their deficiencies by using the capacitor regulators [23]. This type of regulator helps to save power at all speeds of the fan. The idea behind a capacitor regulator is to adjust the voltage across the motor of the fan. In the capacitor regulator, the voltage $V=Q / C$ where $\mathrm{Q}$ is the charge across the capacitor and $\mathrm{C}$ is the capacitance inversely proportional to the voltage. Thus, as the capacitance decreases the voltage and the speed of the fan increases. 
Capacitor regulators present many obvious benefits: They produce no power loss in the circuit, no heat generation, and consequently no extra expense, and it is not bulky. In addition, the capacitor provides linear control of speed [24]. Since they are energy efficient, their power consumption is low and it has no distracting humming sound when the circuit is in operation.

\section{RESEARCH METHOD}

The approach used in this work is the modular approach where the overall design was broken into functional block diagram as shown in Figure 1, where each block in the diagram represents a section of the circuit that carries out a specific function [25].

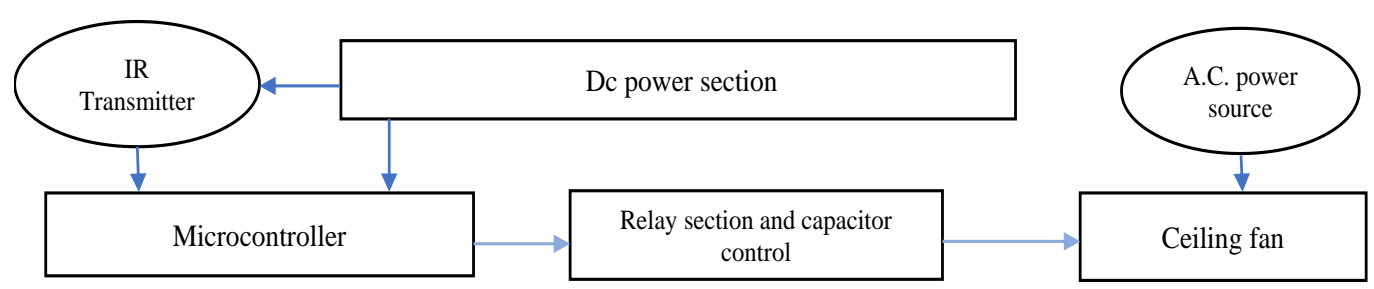

Figure 1. Block diagram of the bi-direction and speed control of the A.C fan

\subsection{Remote control transmitting section}

The remote-control device has the task of sending the infra-red signal, which is received by the infra-red sensor. Its implementation process is described as follows.

\subsubsection{Programming the microcontroller for the remote control}

The AVR (Advanced Virtual RISC) microcontroller was chosen because of its easy usage and the ability to accept programs written in "C++" language. AVR is a family of microcontrollers. FThese are modified Harvard architecture 8-bit RISC single-chip microcontrollers. The programing is divided into two steps. In the first step, a program was written to enable the microcontroller decode the remote hex file. Each remote has a unique hex file. In this project, we made use of a DVD remote control. The decoded hex file is returned to the main program which is the second step of the programing.

\subsubsection{Decoding the remote}

The next step in achieving the remote signal transmission was determined by the transmitter hex file \& for this, we conducted an experiment which involved the use of an Arduino Uno software, Arduino hardware, TFM5560 receiver, a DVD remote and a computer system. The hardware diagram that gave the hex file of the remote is shown in Figure 2. Next, we ran a program. One problem encountered was that our Arduino software had no IRremote.h. This library was downloaded unzipped and installed in the Arduino library. As this was done, we then clicked on the remote button, collected the hex file and then wrote them down. This was used in writing the main program for this study.

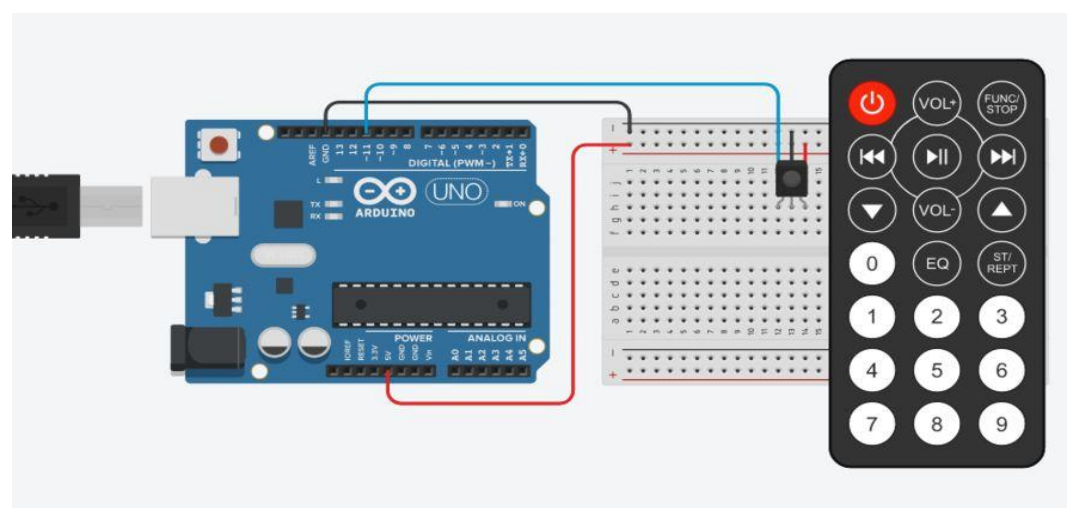

Figure 2. Circuit connection for determining the hex file of the remote 


\subsubsection{Inputting the hex file into the main program}

The main program was written in " $\mathrm{C}++$ " language and the hex file was used as the key element that drives the action in the code. The algorithm of the code is shown in Figure 3, while the main code is contained in appendix B. The algorithm of Figure 3 shows how the program code functions. The IR transmitter sends hex files which is received by the IR receiver. This information selects which relay to click. The relay and the capacitor circuits were connected as the right relay was clicked.

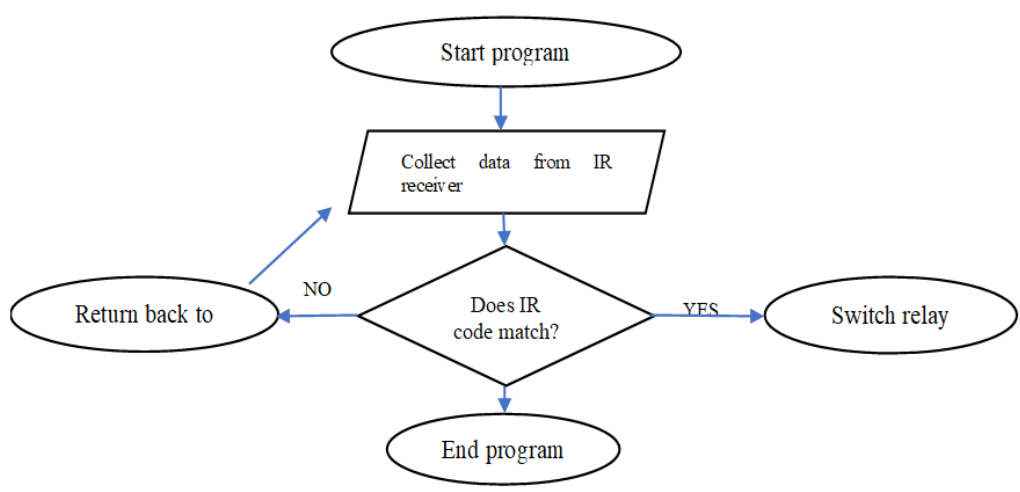

Figure 3. The program algorithm for the hex file

\subsection{The control section}

This section is the control of the fan by the remote through the capacitor function. The remote was decoded and set, a signal was sent from it to the receiver, after which the capacitor and relay circuits received and understood the information and functioned accordingly in speed or direction.

- $\quad$ Operation of the relay and capacitor control circuit

The circuit diagram for the capacitor and relay control is given in Figure 4. Figure 4 design operates on the fact that when a motor capacitor is connected in series with an A.C. source, the voltage across the capacitor decreases, this increases the motor voltage and hence the speed. In other words, increasing the capacitance of the capacitor decreases the voltage across it and hence the speed. The capacitors shown in Figure 4 have different capacitance value. The speed level to be achieved is a function of the capacitance value. The connection and disconnection of the capacitors are achieved by the switching of the relays. Relay RL5 as depicted in Figure 4 is used to change the fan direction of rotation. When the capacitor is connected in series with coil 2 by the NC terminal of the relay, the fan rotated anti-clockwise. In this case, coil 2 is the starting coil while coil 1 is the running coil. When the common is moved to NO, the operation was reversed and the fan rotated clockwise.

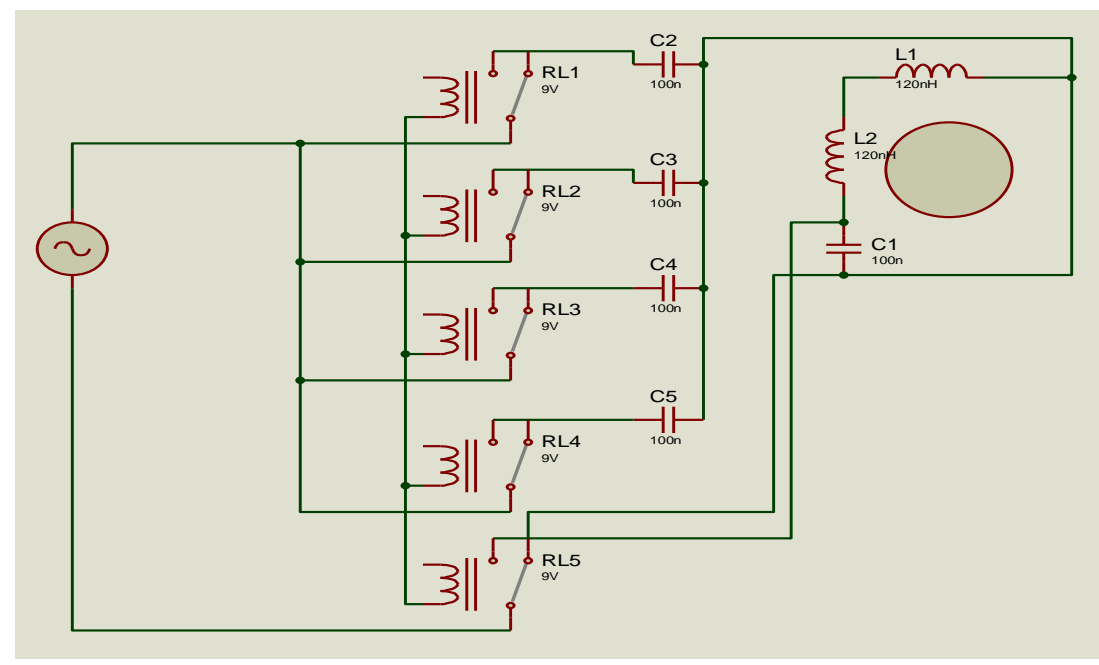

Figure 4. The relay connection and capacitor speed control circuits 


\subsection{Simulation of the circuit using proteus isis software}

The circuit diagram for the control of the relay is shown in Figure 5. The program code in appendix $\mathrm{B}$ was used to control the relays. The circuit also shows the proper connections made from the Arduino UNO to the relays.

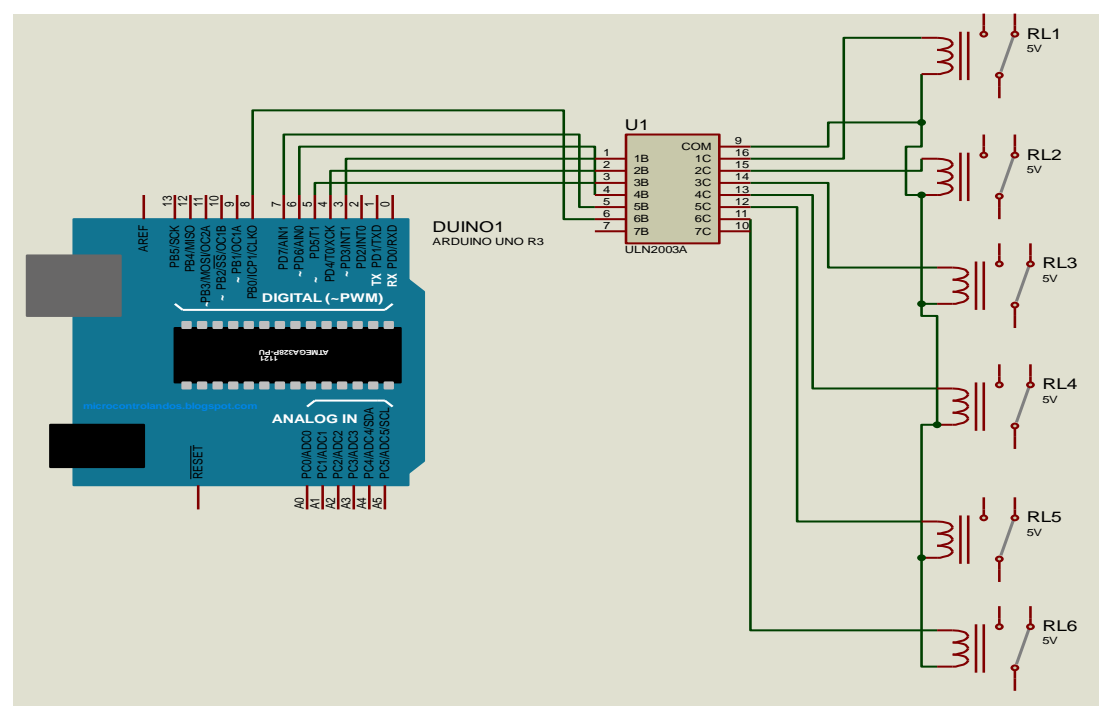

Figure 5. The circuit diagram for relay control

\section{WORK IMPLEMENTATION}

The work was implemented on a printed circuit board and packaged using plastic locally available materials as shown in Figures 6 and 7. From Figure 6, the relay section is seen in blue while the capacitor with different tapings is shown at the left hand-side. The right-hand side is the microcontroller atmega328P-pu it is packaged in Arduino Uno board. The capacitor with different tapping in Figure 7 has 4 tapping points which is responsible for different speed levels.

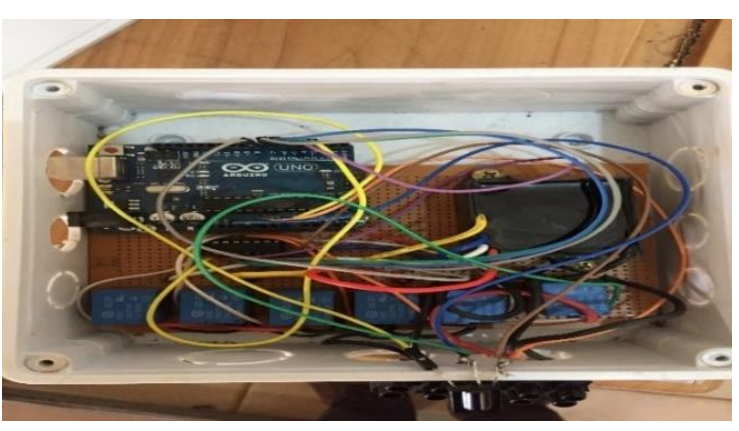

Figure 6. Control circuit implementation diagram

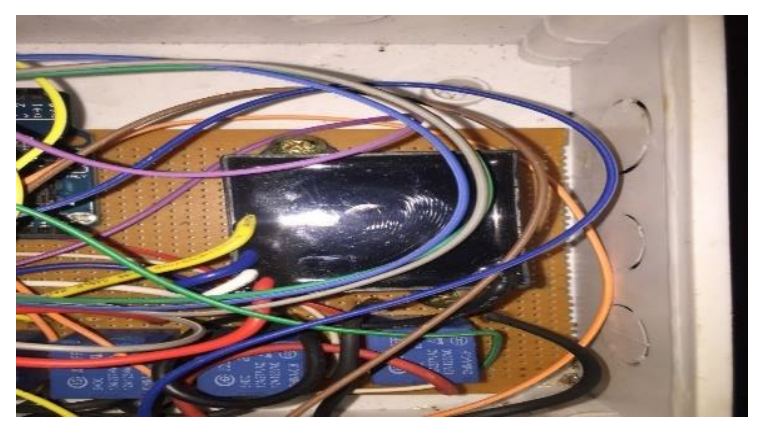

Figure 7. Implemented circuit diagram showing capacitor control with different tapings

\section{- $\quad$ Testing}

The infrared remote-control signal has a carrier signal range of $36 \mathrm{KHZ}$ or $38 \mathrm{KHZ}$. A transmission typically starts with a burst ("on" state) that is used for the automatic gain control (AGC) circulatory in the receiver followed by the "off" state and the actual data transmission. Therefore, the signal can only be "on" or "off" at a time. In the overall circuit shown in Figure 8, the three major components to be connected together are: the fan, the control circuit and the power supply unit. The fan has three terminals namely- first connection from the capacitor $\mathrm{C} 1$, second connection from the capacitor $\mathrm{C} 2$ and the third connection from the live wire L1. The control circuit has 5 terminals namely: regulator R1 which is the first terminal of the capacitor regulator, regulator R2 which is the second terminal of the capacitor regulator, the common ' $\mathrm{C}$ ' 
of the relay which is the neutral input to the fan, the normally open of the relay 'NO' which is an extension for reverse direction and ' $\mathrm{NC}$ ' the normally closed terminal of the relay. The A.C source has two terminals, L live wire and $\mathrm{N}$ neutal wire which supplies power to the system.

\section{DISCUSSIONS AND CONCLUSION}

The study was focused on the development and implementation of a microcontroller based remote control ac fan using infrared frequency. The remote control was able to regulate the speed and bi-directional rotation of the fan. A transmitter was used to send signal at frequency of $36 \mathrm{Khz}$ via an ardiuno microcontroller to the receive circuit that activates the remote operation. The microcontroller was able to understand the command sent by the user through the transmitter. With the knowledge of the new state-of-the art technique in Engineering, the variable speed control and the bi-directional rotation of the fan were achieved at low cost making it possible for people to afford and keep their lives more comfortable. The system was tested and found to meet expected result. From the completed work shown in Figure 9, it can be concluded that speed control of fan using capacitors is very efficient and reliable. The use of capacitors present many obvious benefits as they produce no power loss, no electromagnetic and radio frequency interference, it is cost effective, and not bulky, devoid of humming due to heat dissipation. The system presents better efficiency when compared with other works designed with TRIAC and resistor control methods.

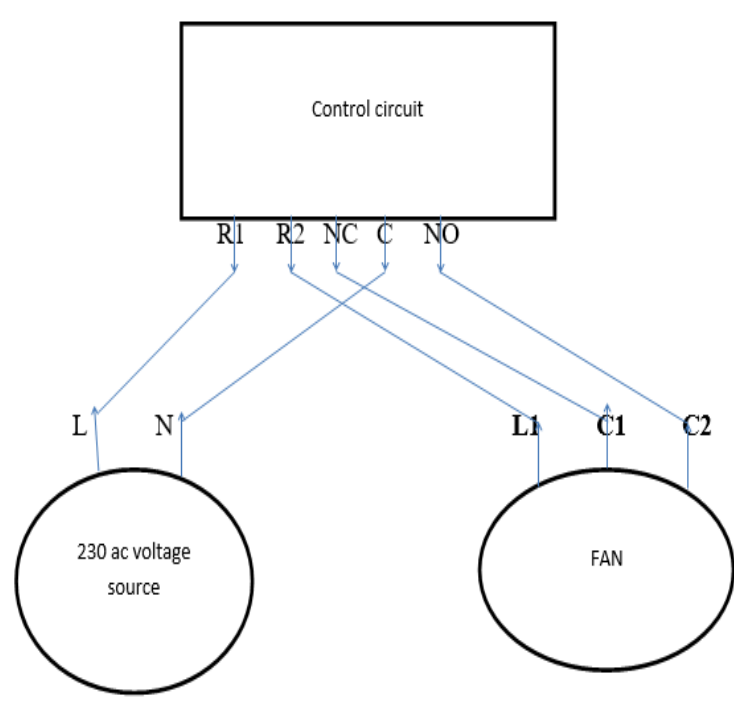

Figure 8 . Test connection diagram of the work

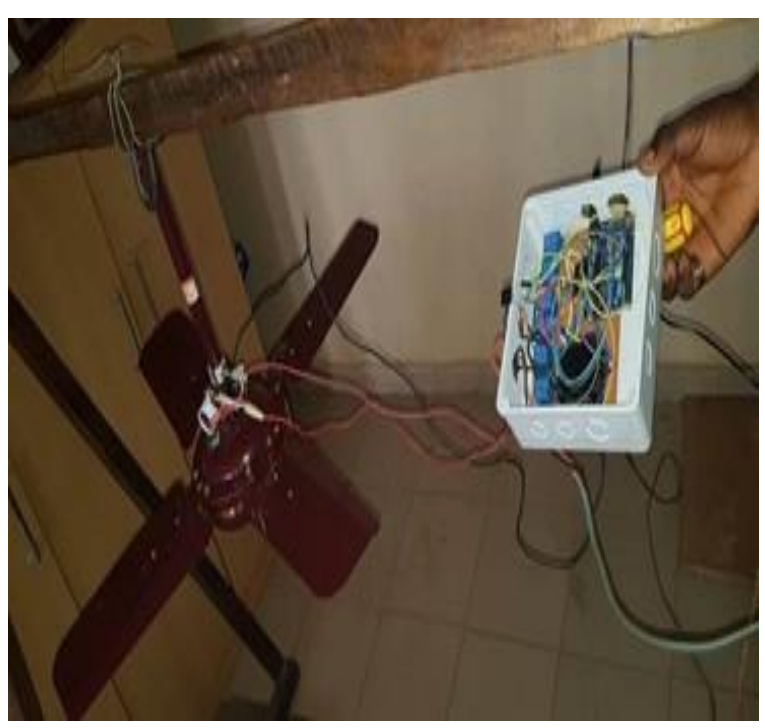

Figure 9. Image of the completed work

\section{REFERENCES}

[1] The News, "The Latest in HVAC Home Automation," The News, p.1, Available: http://www.archnews.com/articles/14160-control-your-castle-the-latest-hvac-home-automation [Accessed February 20, 2019].

[2] Technopedia https://www.technopedia.com/definition/29999/home-automation-system [Accessed February 20, 2019].

[3] Wikipedia, "Home Automation," wiki, p.1, Available: wiki, http://en.wikipedia.org [Accessed February 20, 2019].

[4] N. Dickey, D. Banks, S. Sukittanon, "Home Automation using Cloud Network and mobile devices," Southeastcon 2012 Proceedings of IEEE, pp. 1-4, 2012.

[5] C. Felix, I. Raglend, "Home automation using GSM," Signal Processing Communication Computing and Networking Technologies (ICSCCN) 2011 International Conferencen, pp. 15-19, 2011.

[6] F. K. Santoso, N. C. H. Vun, "Securing IoT for smart home system," 2015 International Symposium on Consumer Electronics (ICSE), pp 1-2, 2015.

[7] S. I. Azid, S. Kumar, "Analysis and Performance of low cost SMS Baes home security system," International Journal of Smart Home, 5, 15-24, 2011.

[8] D. Purohit, M Ghosh, "Challenges and types of home automation systems," International journal of computer science and mobile computing, 6(4), pp. 369 -375, 2017. 
[9] A. Elshafee, K. Hamed, "Design and implementation of a Wi-Fi Based Home Automation System," International journal of computer, Electrical, Automation, Control and Information Engineering, Pp.6, 2012.

[10] S. Osman, K. Chakraborty, A. Islam, N. Rahman, "Design and Implementation of Remote Controlled Fan Regulator", International Journal of Advanced Research in Electrical, Electronics and Instrumentation Engineering, 3, pp. 11682 -11688, 2014.

[11] C. Suh, Y. B. Ko, "Design and implementation of Intelligent Home Control System", IEEE Transactions on Consumer Electronics, 54(3), 2018.

[12] C. K. Das, M. Sanaullah, H. M. G. Sarower, M. M. Hassan, "Development of a cell phone based remote control system: an Effective Switching System for controlling Home and Office Appliances", International Journal of Electrical and Computer Sciences, 9(10). Pp. 23-29, 2009.

[13] K. Gill, S. H. Yang, F. Yao, X. Lu, “A zigbee based home automation system,” IEEE Transactions on Consumer Electronics, 55(2), pp. 422-430, 2009.

[14] F. K. Santoso, N. C. H. Vun, "Securing IoT for smart home system," 2015 International Symposium on Consumer Electronics (ICSE), pp 1-2, 2015.

[15] Pang C. H, Lee J. V. Design of a microcontroller-based fan motor controller for smart home environment. International Journal of Smart Home, 2013, 233-245, 2013.

[16] DIY Zero crosser. "Simple Isolated Zero-cross Detector". DIY ZeroCrosser. [Online]. [Accessed February 20, 2019].

[17] Abel R. "AC Line Powers Microcontroller-based Fan-speed regulator," [Online]. [Accessed February 20, 2019].

[18] C.H. Pang, J. V. Lee, "Design of a microcontroller-based fan motor controller for smart home environment" International Journal of Smart Home, p. 233-245, 2013.

[19] Mahmud A, Abubakar S, Temitope G, Attah P. 'Design and Construction of a Remote Controlled Fan Regulator', Leonardo Electronic Journal of Practices and Technologies. ISSN 1583-1078. Issue 9, p. 55-62, July-December 2006.

[20] Chintha R, Benny P, Vijaylaxmi O, Varsha D, Sanjai P, 'Electrical Appliances in Home Control through IR Remote', International Journal of Innovative Research in Technology, ISSN: 2349-6002, Volume 3, Issue 9, p. 16-19, February 2017.

[21] Ceiling Fan Regulator Circuit. [Online]. Available from: http://www.theorycircuit.com/ceiling-fan-regulatorcircuit. [Accessed26-mar-2019].

[22] Reshmi B. "Speed Control of Fan Using Diac And Triac," International Journal of Engineering Sciences \& Research Technology. ISSN: 2277-9655, p. 429-431, March, 2015.

[23] Fan Regulator. [Online]. Available from: https://www.slideshare.net/nallurulokesh/fan-regulator-65402716. [Accessed: 03-mar-2019].

[24] [PDF] Deki Capacitor Guide Fan Regulators. [Online]. Available from: https://www.dekielectronics.com/pdf/Deki_Fan_Regulators_Feb_2012_web.pdf. [Accessed: 26-Mar-2019].

[25] Madueme VC, Mbunwe MJ, Akuru AB, Anyaka BO. "Design Topology of a Sustainable Remote-Controlled Fan Regulator for Developing Countries,” Renewable and Sustainable Energy Reviews. Vol 71, p. 639-644, May 2017.

\section{BIOGRAPHIES OF AUTHORS}

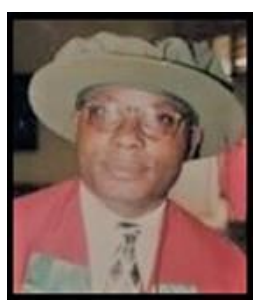

Boniface O. Anyaka is currently a Senior Lecturer in the Department of Electrical Engineering, Faculty of Engineering, University of Nigeria, Nsukka, Nigeria. He had his M.Eng in Electric Power System/Applied Automatics from the University of Technology, Wroclaw, Poland in 1988 and his Ph.D. from the Department of Electrical Engineering. University of Nigeria, Nsukka in 2011. He has held a number of positions in the university system. He was the director, student's industrial work experience scheme (SIWES), University of Nigeria Nsukka and Enugu campuses (2006 - 2008). He was the acting Head, Department of Electrical Engineering, University of Nigeria, Nsukka (2011-2013) and the immediate past Associate Dean, Faculty of Engineering, University of Nigeria, Nsukka (2016-2018) Engr. Dr. Anyaka is a registered member of the Council for the Regulation of Engineering in Nigeria (COREN), corporate member, Nigeria Society of Engineers (NSE), member, Solar Energy Society of Nigeria (SESN), and Member Nigeria Institution of Electrical and Electronic Engineers (NIEEE). His major field of research interest is in the areas of power system modelling and renewable energy (Photovoltaic). He has to his credit, over 50 publications in both local and international journals.

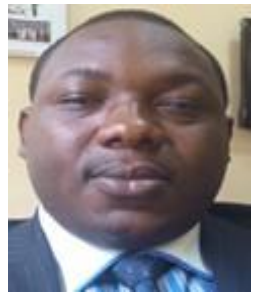

Ene Princewill Chigozie is a researcher under the Instrumentation and Robotic Control group at the Exxon Mobile Laboratory, Faculty of Engineering, ESUT. He obtained a B.Sc. Degree in Electrical and Electronic Engineering and M.Eng. Degree in Instrumentation and Control Engineering from EEE Dept. ESUT in 2006 and 2012 respectively. He is a member of Nigerian Society of Engineers (NSE), Council for the Regulation of Engineering in Nigeria (COREN), Institute of Electrical and Electronic Engineers (IEEE). His scientific interests include Artificial Intelligence in Robotic Control, Mechatronics, signal Processing, Computer Vision, and Power System Security. He has collaborated actively with researchers in other disciplines of engineering. 


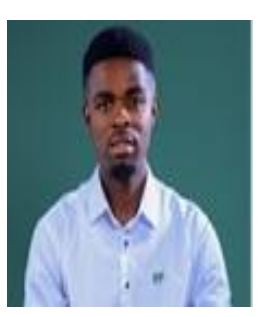

Fortune C. Amanze is a graduate researcher at the Department of Electrical Engineering, University of Nigeria, Nsukka Enugu State, Nigeria. His research interest is in the field of Power Systems, Control Engineering and Renewable Energy Systems.

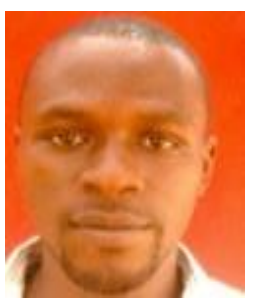

Engr. Luke Uwakwe Omeje, B.Eng. 2014, M.Eng. 2019. He is a Staff in Department of Electrical Engineering, University of Nigeria, Nsukka His research interest is Power System Modelling. He is also a Registered Member of the Council for the Regulation of Engineering in Nigeria.

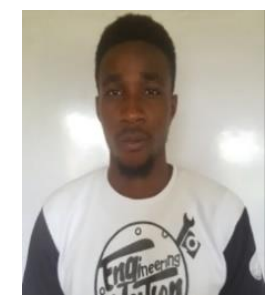

Kenneth C. Chike holds a bachelor degree in Electrical and Electronics Engineering from Igbinedion University, Okada, Nigeria. He is currently a masters Engineering student in the Department of Electrical Engineering, University of Nigeria, Nsukka. His Research area interest is in Power Systems Engineering and Renewable Energy. 